\title{
THE PROBLEM OF THE PUPIL WHO FAILS.
}

\author{
By Marion Sykes, \\ Bowen High School.
}

The problem of the pupil who fails is an ever-present one. It is the question of how to reduce the amount of waste in our business, a question of especial importance in the management of the school, for not only does it mean waste of public funds, but what is far more serious, waste in human lives. To the fact that the time of those who fail is used not only to no advantage but often to the pupil's positive disadvantage, is added the unfortunate result that the time of the many industrious pupils is sacrificed, while the attention of the teacher is given to the few indifferent ones. We deplore the attitude of many pupils, their lack of responsibility toward school work. We are unable to understand their willingness to come to class with lessons unprepared. Even the easy lesson assigned the first day is cheerfully neglected. If the trouble lay with pupils of one subject or group of subjects, with a few teachers, or a few schools, the inquiry into causes and remedies would be limited; but these unfortunate conditions are found in the case of pupils of all subjects, with all teachers, in all schools. The inquiry must be a broad one which will include conditions as they effect pupils widely.

The records of the school indicate a -waste of time which ought not to be. Too many fail of promotion into the next grade. In one high school eighty-one per cent of the membership of the September classes were promoted last June. Ninety-one per cent of the fourth-year pupils were graduated; ninety-four per cent of the third-year pupils entered fourth year; eighty-eight per cent of the second year pupils entered third year; sixty-nine per cent of the first-year pupils were promoted to second year. Of the first-year boys, fifty-seven per cent were promoted, seventy-eight per cent of the girls. In reducing the number of failures it is evident that attention should be given especially to conditions in our first-year classes. Of course the worst cases never become second or third-year pupils, just as the worst cases in the elementary schools never get to the high school., Of those who are promoted into the next grade, too many are behind in one 
or more subjects. Of those promoted from the first year to the second year in the high school mentioned, thirty-seven per cent were behind in one or more subjects; fifty-nine per cent of the boys, twenty-four per cent of the girls.

In spite of this we pass many who we feel are not deserving of the credit we give them. We lack the courage to fail all those whose work has really been unsatisfactory. Too many fail in our schools, but often too many who ought to fail are passed by the individual teacher. Just here is one way in which the school falls short of the moral training it owes the child. How can the giving of credit to a boy or girl who knows that he has done poorly and whose companions know that he has done poorly, strengthen the character of the pupil himself or of the other members of the class?

Some say that so many fail in the several subjects because one standard of seventy-five per cent in each subject is too high. So it would be if seventy-five per cent meant that the pupil had done three fourths of the work. No one but our critics think that. Seventy-five per cent means passable and might as well be sixty-five or even fifty per cent. A lower passing average would not mean that we would put more pupils through but that our marks would show more nearly what part of the work had been done. As it is, in most cases, fifty is "the highest mark which stands for zero." The requirements for promotion from first to second year are liberal. If a pupil has done passable work in all subjects he receives four credits or more at the end of the first year. $\mathrm{He}$ is promoted if he has received three credits, if he has passed in three fourths of his work. That surely is not exacting. Failure to pass does not necessarily mean that a pupil has received no benefit from his work. Often he has really improved and when he goes over the subject a second time, he finds himself and does well.

In looking for causes and remedies it is well to consider the conditions found in the elementary school before considering those in the high school. This is a difficult portion of the subject to approach because of the certainty of being misunderstood. There is no desire to criticise the elementary teacher. The fault is in the system. When we consider the conditions under which the elementary school is working, the wonder is not that the pupils do so poorly when they 
come to us, but that they do so well. The fact that the worst conditions are in the first year, that the children at the beginning of their high school life make so little effort to do the work assigned them, indicates that no real improvement can be made without beginning with the elementary school.

One trouble with the children is the unfortunate understanding of certain psychology. It has been urged upon the teacher to arouse the child's interest. Does arousing interest consist in amusing the child? Is interest to be gained only by firing a pistol or engaging in a procession? If we receive only involuntary attention which does not lead into voluntary attention the child is not being prepared for his place in life. Dr. Münsterberg asks, "May it not be that the most important aim of education is just the power of overcoming the temptations of mere personal interest, the power to serve purposes which demand effort of will and discipline of attention?" The result seems to us too often "a flabby inefficiency, a loose vagueness and inaccuracy." Our education must be such that those who go out from us will not continue "to follow without check their untrained impulses." Another doctrine which has been distorted is that the responsibility is on the part of the teacher. If she but do her duty the pupil cannot help but learn. This has been pushed to such an extreme that the pupil has unconsciously absorbed it. Often his attitude seems to be "interest me and I'll ao well; but I myself have nothing to do."

There are other causes, however, which are more effective in bringing about the results we deplore. Often the pupils are handicapped physically. Bad tonsils, adenoid growths, poor eyesight, defective hearing, flat foot, and lack of sufficient food of the right sort are often to blame for backwardness. Fortunately society is waking up to the tremendous physical handicap placed on some children. The child-study department is ready to help teachers toward a solution of the difficulties of such pupils, and in some cases special instruction is provided. The school system is working to reduce the ill effects of such conditions.

Some think that the system of passing pupils from grade to grade below the high school on a general average of seventy-five per cent, means necessarily a failure on the part of certain pupils in certain subjects. In some elementary 
schools the marks in writing, drawing, music, composition count as much toward promotion into the next grade as the marks in reading, arithmetic, history, or English. Some children may pass on very good averages who never stood above sixty in arithmetic for example. Of course such a child could not make the necessary seventy-five per cent in algebra required in the high school. This method of promotion would result as claimed in the case of certain children, but on the whole it seems as good a method as any for promotion in the grades below the high school.

There are four other causes which are much more unfortunate in their results than any mentioned thus far. They are the large number of pupils under the charge of one teacher in the lower grades, the crowded condition of the curriculum, the character of the text-books used, and the bad habits of the pupils themselves. In the elementary school the average membership of forty-five in a room is not so large as formerly when teachers of the third grade, for example, had in some cases fifty-seven under their charge. The rule works out an average of from forty-five to forty-eight in a room with a tendency to fewer in the higher grades. This is in advance of what it used to be but there are still too many. With such large numbers how else can the teacher do but treat the pupils in the mass, accept short, scrappy answers, and push on as many as possible to make room for the incoming crowd? She aims to demand careful answers, to give each child some individual attention; but the teacher can do only her best with the large number of pupils in her care. We object to our large classes in the high school, and we deplore the lack of responsibility shown by the child. We will not succeed in the results we wish until the large numbers in the rooms in the lower grades are reduced. This is a difficult matter to adjust, for a large city like Chicago grows so rapidly that the schools do not easily keep up with growing and changing population. Then there is a mysterious something called "business interests," which makes it better economy to save dollars and cents, rather than boys and girls.

The crowded curriculum is another difficulty with which the elementary school must contend. The mastering of all the work laid down for the elementary school is an impossibility. Attempts to cover the work would seem to result in 
confusion with little or nothing done well. Besides the large amount of work in each subject to be done, new subjects or new phases of old subjects are introduced in a way which means a crowding out of something to give time. This class of difficulties may be illustrated by the experience of a secondgrade teacher. She had a room of forty-five pupils whose program allowed ten minutes a day for physical culture. She was instructed to make dancing a part of this work. Not being able to teach forty-five children to dance by giving them ten minutes a day, and being obliged to put in the dancing, she had to take time from other subjects. Lessons in reading are required to be dramatized. The time allotted to reading on the program must be extended to allow of any results worth the name. It is not my intention to urge against folk dancing or dramatizing in themselves, but to urge that when those in authority wish these things to be included in school work the program be so adjusted that they aid the pupil in his study of the fundamentals, not crowd out the fundamentals. Too often construction work unrelated to other subjects is introduced in the same way, and there fails to be laid the foundation needed by all American citizens no matter what their life work is to be. A boy who was in his second year in the high school was overheard to say to a first-year girl, "What did you fail in? Algebra?. Bet I know what school you came from. Same as I did. Scissors and cardboard, cardboard and scissors, but not much arithmetic."

Accounts of the work of teachers in getting up programs for school entertainments come to us and we hear of how a teacher leaves her class work and drills groups of pupils who have left their work. We wonder if the pupils have sained more than they have lost. We know that our work could not stand that sort of thing.

The character of the text-books used in the elementary schools is another serious drawback. Many of the books are beyond the comprehension of the pupils. It is impossible to expect the child to take the book and get anything from it for himself. He cannot learn to read from such a book, and his best efforts result too often in discouragement and confusion. No wonder that he gets into the way of coming to class not with a poorly-prepared lesson, but with a lesson which he has made no attempt to prepare. In some cases 
there seems to be no book written on the subject which is within the comprehension of the child. Yet it surely is a part of the work of the school to teach the pupils to take a book and get out of it valuable information.

The worst condition to contend against is bad habits on the part of the pupils themselves. Take for example smoking on the part of small boys. They tell us that of twenty-four hundred smokers whose record was examined, less than one hundred and fifty were up to their grade in school. That of the boys from two to four years behind in their grades most of them smoke. With smoking go physical defects, and bad habits which make it difficult for a boy to develop will power.

These are some of the drawbacks against which the elementary school is working. If our failures in the high school are to be reduced in numbers, improvement must begin in the elementary school with fewer pupils to a teacher, a simplified curriculum, easy texts within the comprehension of the pupils, and a coöperation of home, school, and social interests which will work against poor health and bad habits of the pupils.

In the high school conditions of the same general character as those in the elementary school are met. Our point of view is an important matter. Too often this has been that of the specialist, not the point of view of the child. If we find the pupil unable to do what is our idea of high school work, then we should give him what he needs, not what we think the ideal pupil ought to have. Our methods, our subject-matter must be adjusted to the needs of the pupil who comes to us, not to the pupil who, we think, ought to come. If our pupils need what we consider seventh-grade work, then we should give them seventh-grade work. We are often too much afraid of making our work easy. The hopeful thing about this situation is that we are improving and our point of view is becoming more and more that of the child.

We are afraid of being judged mere hearers of lessons rather than teachers, and in order to avoid such an imprecation we sometimes assign very little definite work. We must make assignments for daily work definite, and the pupil must be held responsible for the preparation of all work assigned. Passing pupils who have habitually done slipshod work not only results in sending into higher classes poorly 
prepared pupils, but it has a bad moral influence on the children themselves.

The numbers in our classes seem to many of us to make it impossible that a large per cent can pass. Our largest classes are in the first year where the failures are the most. The people who are failing need individual attention. We all know that with forty-five pupils reciting in fifty minutes, few can get individual attention. Those who go to class unprepared are the same ones who go to the study room with nothing to do, or with a story book to read. That is one of our perplexing questions, "Why is a pupil willing to loaf out a study hour and go to a recitation the next period with the lesson unprepared?"

Our texts, as well as the texts in the elementary schools, have not always been adapted to our pupils. They are written by specialists who often have not the pupil's point of view. This condition is steadily improving. We are getting rid of some books which are too difficult or which are inadequate.

The matter of the habits of the pupils is a serious one, especially the habits of the boys. In one high school it was found that of the first-year boys who had been in school a year last June but who were behind in one or more subjects, thirty-six per cent were known to smoke. Seventeen per cent of those behind in one subject.smoke, eighteen per cent of those behind in two subjects, sixty-eight per cent of those behind in three subjects, and sixty-one per cent of those behind in four subjects are known to be smokers. Of those who passed in all subjects none smoked. Smoking is a habit which accompanies other habits, all of which work against the mental growth of the boy. I made a list of those I call the "boldest smokers," those who will stand smoking, leaning against the schoolhouse almost at the very doors unless they know a teacher is coming. They are all pupils, who fail in subject after subject, pupils who have taken the time and attention of teachers and principal for repeated disorder.

What about the girls who fail? I don't know. In the case of some their health is poor, most seem to be plain lazy, a few unable to do the work of the class. If we could bring the proportion of boys who pass up to the proportion of girls who pass we would be a long way ahead. I asked some of the boys about it. They said, "When school is out" a girl has to 
go home. At least her people know where she is. When school is out a boy goes to the gym or the park; maybe he bums around a street corner and goes to the show or pool room, and gets home in time for supper." It used to be said that introducing manual training and shop work would hold the boys. We find that with only few exceptions, those doing well in academic subjects do well in shop, and those failing in academic work do poorly in shop.

The subject is a large one. What can teachers do to help? It will not help to mark all pupils through. We wonder if our influence would be of any use in bettering the conditions in the grades. We can adjust our work continually to fit the pupil as he comes to us, not as we think he ought come. We can continually point out the handicap a pupil has when he is a member of a crowded class. When a change of textbooks is probable, we can use our influence toward a simple book which the pupil can actually read and understand, and which is definite and adequate. How can we work effectively against bad habits which undermine the mental power, the will, the character of our boys, habits which were formed outside of school, before they came to us?

\section{EPIDEMIOS OF SO-CALIED INFLUENZA.}

Since the pandemic of influenza in 1889-90, when within one year the whole civilized world was afflicted with the contagion, there have been lesser outbreaks at irregular intervals in most centers of population. These epidemics of sore throat and bronchitis have usually been called influenza or "la grippe," because of the characteristic contagiousness of the infection, the persistence of the symptoms, and the tendency to prostration and mental depression. But this diagnosis has not been satisfactorily confirmed by bacteriologists. In the great pandemic, Pfeiffer and others found in the nasal and bronchial secretions "pure cultures of the influenza bacillus in all uncomplicated cases." Subsequent reports seem to indicate that the influenza bacillus is a common invader of the airpassages in a large group of other diseases, notably whooping-cough, phthisis and measles. There is no evidence that this bacillus is more prevalent in the local epidemics of influenza than in the ordinary catarthal infections. A recent epidemic of "septic sore throat" in Boston was studied by Richardson and others. They traced the contagion to infected milk. A study of an influenza epidemic among children in Berlin and of the recent epidemic of sore throat in Chicago have demonstrated as the exciting agent a germ of peculiar characteristics different from the influenza germ. The Journal of the American Medical Association points out that these three epidemics occurring during the last year in widely separated communities, have all been caused by the same germ. It is to be hoped that in the future such epidemics in various cities will be more systematically and carefully investigated. 